\title{
A narrative review of current therapies in unilateral recurrent laryngeal nerve injury caused by thyroid surgery
}

\author{
Hedi Tian, Jun Pan, Linghui Chen, Yijun Wu \\ Department of Thyroid Surgery, the First Affiliated Hospital, School of Medicine Zhejiang University, Hangzhou, China \\ Contributions: (I) Conception and design: H Tian; (II) Administrative support: Y Wu; (III) Provision of study materials or patients: H Tian; (IV) \\ Collection and assembly of data: H Tian, J Pan, L Chen; (V) Data analysis and interpretation: H Tian, J Pan, L Chen; (VI) Manuscript writing: All \\ authors; (VII) Final approval of manuscript: All authors. \\ Correspondence to: Yijun Wu, MD. Department of Thyroid Surgery, the First Affiliated Hospital, School of Medicine Zhejiang University, Hangzhou \\ 310003, China. Email: wuwu5925@zju.edu.cn.
}

\begin{abstract}
Objective: To summarize and compare current common treatments in recurrent laryngeal nerve injury (RLNI). In addition, we introduced nerve tissue engineering technology in RLNI animal models. This review is a comprehensive summary of current therapies for unilateral RLNI.

Background RLNI is a common complication in thyroid surgery. Although preoperative imaging and intraoperative nerve monitoring are widely applied, some damage to nerves is still inevitable. Currently, advances in nerve repair and regeneration have been made, but relatively few studies have focused on RLNI. In this review, we summarized and compared current common treatments in RLNI.

Methods: We searched the literature on PubMed and Web of Science, and chose studies about RLNI in thyroid surgery. Keywords included the following terms: "recurrent laryngeal nerve regeneration", "injection laryngoplasty", “type I thyroplasty”, “arytenoid adduction”, and "nerve tissue engineering technology”. Only English language studies were included. In the section on nerve tissue engineering technology, we described the application in detail in the table below.

Conclusions: Currently, the majority of treatments could obtain different effects to some extent, but there are still shortcomings that need to be overcome further overcome. Therefore, potential exploration such as nerve tissue engineering technology is worthy of attention.
\end{abstract}

Keywords: Recurrent laryngeal nerve injury (RLNI); nerve regeneration; nerve tissue engineering technology

Submitted Oct 19, 2021. Accepted for publication Dec 24, 2021.

doi: $10.21037 /$ gs-21-708

View this article at: https://dx.doi.org/10.21037/gs-21-708

\section{Introduction}

Recurrent laryngeal nerve injury (RLNI) is a common complication after thyroid surgery, especially in patients with malignant tumor invasion or reoperation. The incidence of RLNI varies in different studies, and it is usually lower in some clinic centers due to dissection visualization and intraoperative nerve monitoring (IONM), with incidence rates of approximately $1-2 \%$ (1). There are some potential factors related to RLNI including surgeon operation volume, surgical manipulation, nerve anatomy, and tumor invasion. RLNI occurs unilaterally or bilaterally, leading to vocal cord paralysis (VCP). The symptoms of RLNI include dysphonia, dysphagia, dyspnea, even apnea. Dysphonia that caused by unilateral VCP disturbs an individual's quality of life, work and activities. After bilateral VCP, patients will need emergency tracheotomy or surgical intervention. In addition, RLNI can be divided into non-transection injuries (including traction, thermal, compression, clamping, ligature, entrapment, suction) and transection injuries in thyroid surgery (2). To avoid nerve injury, the surgeon must carefully expose and isolate the RLN during thyroid surgery. Furthermore, IOMN is widely used and recognized in surgery. On the one hand, 
IOMN can help surgeons distinguish RLN location, with timely adjustment of the opposite operation when the unilateral signal disappears $(3,4)$. On the other hand, IOMN also indicates the extent of nerve damage by the degree to which the signal disappears, which will benefit subsequent diagnosis and treatment $(2,5)$. Due to numerous uncertain factors during surgery and unsatisfactory preventive measures, the application or development of therapeutic strategies after RLNI is particularly important.

Nerve injury can cause severe of motor and sensory dysfunction. Spontaneous recovery is slow in peripheral nerve injury (PNI), progressing at a rate of approximately $1-3 \mathrm{~mm}$ daily, and is slower in central nerve injury (CNI) (6). Nerve injury and regeneration are complicated processes. After nerve injury, Wallerian degeneration occurs in the distal axon. Hours later, Schwann cells (SCs) and macrophages clear axons and myelin debris (7). This provides a permissive condition for nerve regeneration. The inflammatory reaction can clear necrotic tissue, but can also cause secondary damage (8). Reactive astrocytes also have dual effect. On the one hand, reactive astrocytes are beneficial for blood-brain barrier repair and wound healing. On the other hand, scar-forming astrocytes can inhibit axon regeneration $(9,10)$. Neurotrophic factors (NFs), cell adhesion molecules, extracellular matrix, and appropriate environment are essential for nerve regeneration (11).

To date, there are various therapies for nerve regeneration, including non-surgical treatments (e.g., drugs, electrical stimulation), neurorrhaphy, nerve transplantation, and neural tissue engineering. Generally, several therapies are combined to achieve better prognosis. Nerve tissue engineering is a recently developed but promising therapeutic approach. At present, it is rarely applied in the clinic. Considering the essentiality of the nervous system, the studies on its regeneration and functional recovery are well underway. However, research on recurrent laryngeal nerve (RLN) has not been extensive. If RLNI occurs during operation, direct suture, neuroanastomosis and reinnervation can be presented. When the RLNI is found post-operation, we can choose observation within a short time period, and administer drugs. The function will possibly be able to recover after a period of time. If the discomfort does not improve, other steps, such as reoperation, neuroanastomosis, reinnervation, and nerve tissue engineering technology, should be taken. In addition, there are some remedies in view of the symptoms after RLNI. These methods act on anatomical structures, including injection laryngoplasty (IL), type I thyroplasty and arytenoid adduction (AA). In the following content, we summarize several common therapies after RLNI (Table 1). Although the transection injury incidence is slow in RLNI, VCP will be permanent (100\%) without any intervening measures. Given the reports that the majority of non-transection injuries will recover without any management (2), so we focused on transection injury therapy.

We present the following article in accordance with the Narrative Review reporting checklist (available at https:// gs.amegroups.com/article/view/10.21037/gs-21-708/rc).

\section{Discussion}

\section{Therapy of non-transection injury}

In some situations, the nerve non-transection injury may not be recognized by the naked eye but may be identified by the IOMN signal. Surgeons not only carefully expose and isolate RLN but also consider the use of electrotomes, harmonic scalpels and so on. Drugs (e.g., neurotrophic drugs), speech therapy or nerve exploration and decompression can be considered. An experience showed that patients with ligation injury achieved complete voice recovery when they received RLN liberation surgery within 3 weeks (12). When injury is severe and reaches the nerve endoneurium, possibly caused by thermal or severe mechanical damage, recovery is difficult $(13,14)$. Surgery can be used. For example, end-to-end neuroanastomosis achieved pronounced effects in sutures and thermal injury (15). We will introduce surgery in the following sections.

\section{Therapy of non-transection injury}

\section{Direct suture}

When the injured nerve gap is less than $5 \mathrm{~mm}$, without tension, direct suturing is possible (16). Neurorrhaphy could improve voice quality, aspiration and the Grade, Roughness, Breathiness, Asthenia, Strain (GRBAS) score, and prevent vocal cord atrophy. Plenty of experiments have proved that end-to-end suture was useful $(15,17-19)$. Bhatt et al. used laser welding of the RLN instead of microscopic suturing of the RLN in nerve transection animal models. They found that the strength of vocal fold adduction was greater in the laser welding group than in the microneural suture group (20). Due to the development of microscopy technology and new material, the nerve sutures have evolved. However, there are still some problems that need to be solved in neurorrhaphy. Because 
Table 1 Comparison of therapies after recurrent laryngeal nerve injury

\begin{tabular}{|c|c|c|c|c|c|}
\hline Characteristic & Directly suture & $\begin{array}{l}\text { Neuroanastomosis } \\
\text { and reinnervation }\end{array}$ & $\begin{array}{l}\text { Injection } \\
\text { laryngoplasty }\end{array}$ & $\begin{array}{l}\text { Type I thyroplasty and } \\
\text { arytenoid adduction }\end{array}$ & $\begin{array}{c}\text { Nerve tissue } \\
\text { engineering technology }\end{array}$ \\
\hline Re-operation & Not required & Maybe required & Not required & Required & Required \\
\hline \multirow[t]{4}{*}{ Short-coming } & $\begin{array}{c}\text { Secondary nerve } \\
\text { damage }\end{array}$ & Donor nerve selection & Laryngeal edema & Laryngeal edema & Toxicity of materials \\
\hline & $\begin{array}{l}\text { Misdirected } \\
\text { regeneration }\end{array}$ & Suitable size of nerve & Infection & Infection & Immune rejection \\
\hline & Laryngeal spasms & & Hemorrhage & Hemorrhage & Tumorigenesis of cells \\
\hline & & & Foreign body reaction & Foreign body reaction & \\
\hline
\end{tabular}

there are more innervated adductor nerve fibers than abductors in the larynx, the vocal cord may be immobilized in middle position, which can aspiration reduction and tension restoration, but normal vocal fold movement may not recover (21). Moreover, direct suture may cause the main problem called "misdirected regeneration", which may be attributed to the mixing of abductor/adductor or motor/sensory fibers during regeneration $(22,23)$. This phenomenon prevents the resumption of normal movement, and even potentially causes laryngeal spasm. Despite existing drawbacks, direct suture is still the preferred option, as it is simple, fast, and effective and can help the patient to avoid secondary surgery. Compared with nerve implantation and neuromuscular pedicles, neurorrhaphy had the best performance in nerve regeneration (23).

\section{Neuroanastomosis and reinnervation}

When the nerve gap covers a distance of more than $5 \mathrm{~mm}$, neuroanastomosis and reinnervation should be considered. Ansa cervicalis nerve (ACN)-to-RLN anastomosis is the common neuroanastomosis method (24). In some situations, when completely removing a tumor that infiltrates the RLN, the RLN is inevitably injured. In a previous report, immediate ACN-to-RLN anastomosis during surgery fortunately protected phonatory function restoration, and guaranteed oncological radicality (25). In addition, ACNto-RLN anastomosis not only restored a relative normal voice, but also improved dysphagia (26). Moreover, the effect of ACN-to-RLN anastomosis was superior to those of IL and thyroplasty in several studies $(27,28)$. ACN is the commonly viable option in RLN reconstruction. However, other nerves are available when the ACN is hard to obtain or unsuitable. There were no significant differences between the great auricular nerve (GAN) reconstruction with the RLN and ACN to RLN anastomosis in a previous study (29). A follow-up study about the of 237 cases with ACN reinnervation showed that phonatory function could be normal after nerve-grafting (23). For patients with RLNI, free nerve grafting was used between the RLN stump and the ACN stump and showed that all patients obtained satisfactory outcomes (30). Additionally, in bilateral vocal fold paralysis, the vocal function was also improved significantly after selective reinnervation (31). When researchers directly chose the nerve to the thyrohyoid (TH) muscle for reinnervation, this also resulted in good outcomes (32). In another study, patients received combination therapy including nerve reconstruction and nimodipine. The results indicated that the voice handicap index (VHI) of patients could steadily improve, and there were no obvious adverse reactions due to the addition of drug treatments (33). Although nerve grafting is the gold standard, it also has some shortcomings. Neuroanastomosis and reinnervation may require reoperation. The surgical effect may manifest after a period of time (34). Reinnervation will also lead to misdirected regeneration, and even cause the function of donor innervation area loss.

\section{Injection laryngoplasty}

When RLNI occurs, the vocal cord is fixed and the glottal closure is slightly incomplete. IL can increase the volume and mass of the vocal cord by injecting implants, and thus improve glottal closure and vocal cord vibration. The implant materials included homograft, xenograft, autograft, and synthetic materials (35). Sorting by permanent (long- 
lasting) and temporary(short-lasting) materials, shortlasting material may be preferred in potentially recoverable unilateral vocal cord paralysis (UVCP) so that later recovery will not be affected (36). Among these materials, with features including easy injectability, good biocompatibility, and favorable biomechanical properties, hyaluronic acid (HA) was widely used (37). HA could improve voice quality and parameters. However, HA may degrade within only a few months. Even so, some studies have shown that HA injection can achieve long-term effects $(34,38)$. Compared with HA, fat as an autograft is inexpensive, easily available, and can achieve durable effects. Patients were injected with autologous abdominal fat in the vocal cord. After a period of follow-up, the objective and subjective voice scores of all patients were improved. In addition, the study yielded a lasting result (39). IL produced therapeutic efficacy regardless of the use of temporary and permanent VCP (40). Studies have shown that early injection achieved a better prognosis $(36,41)$. There are several advantages including ease, lower invasiveness than surgery, and repetitive operation in IL. However, compared with reinnervation, IL may not be as effective as surgery after a long time of comparison. In addition, the clinical effect of IL is significantly influenced by injection time and materials (42). An implant may cause an inflammatory response, laryngeal edema, hemorrhage. Voice quality can continue to improve if IL is used as an adjuvant to voice therapy (43). Interestingly, studies have pointed out that vocal fold injection can play a temporary role in early UVCP before the effect of nerve reconstruction appears (44).

\section{Type I thyroplasty and AA}

When glottal closure is severely insufficient, the surgeon can insert an implant at the vocal cord the plane of the thyroid cartilage. Similar to IL, the implants used for the vocal fold is various. Silicone elastomer, polytetrafluoroethylene paste, pre-molded silastic, calcium hydroxyapatite and titanium are widely used (45). Titanium achieved better outcomes in the current study (46). AA plays a part in UVCP treatment by directly stretching arytenoid cartilage directly. AA is usually adjuvant medialization procedures (46-48). A novel endoscopic AA with IL was developed as a rapid, minimally invasive solution for UVFP (49). There were adverse events associated with thyroplasty, including hematoma, infection, and implant extrusion (50).

\section{Speech therapy}

Speech therapy can be used in the first measures or adjuvant therapy when patients have voice disorders caused by RLN injury. Although an additional surgical procedure is not required in speech therapy, good health habits, massage the laryngeal and undergo vocalization training need to be maintained (51). Reports have shown that voice therapy could improve voice quality of patients and reduce patient anxiety $(52,53)$. Voice therapy could maintenance therapy when it is as an adjuvant therapy (43). In some cases, owing to tension imbalance after medialization procedures (type I thyroplasty, vocal fold injection and AA), voice therapy can improve dysphonia by supporting vocal fold tension (54). However, this therapy requires the cooperation of various department doctors (including speech-language pathologists) and multiple treatments (51). More controlled clinical trials are needed to prove effects.

\section{Nerve tissue engineering technology}

Due to the unsatisfactory effects of various previous treatments, nerve tissue engineering technology is now widely studied in nerve regeneration, including RLN regeneration [Table 2 (55-59)]. This technology uses conduits or scaffolds with cells, factors, and matrix to mediate RLN regeneration, which could create an environment that is more conducive to nerve growth than other treatments. Chitose et al. utilized a collagen scaffold containing SCs to repair a $20-\mathrm{mm}$ RLN gap. Axon regeneration and vocal fold adduction occurred in two months (60). Human umbilical mesenchymal stem cells (HuMSCs) and nerve growth factor (NGF)loaded heparinized collagen scaffolds (HuMSCs/NGF HC-scaffolds) were also used to repair RLN in rabbit models. At 8 weeks, the results showed that HuMSCs/ NGF HC-scaffolds group achieved an approximate normal electromyogram and had a higher level of nerverelated proteins than the other control groups (61). Polyglycolic acid (PGA) coated conduits provide a favorable environment for nerve regeneration. Higher vascular proliferation and more axons were found when nerves were repaired with PGA coated tubes (55). In another study, SCs and neural stem cells (NSCs) co-cultured in lamininchitosan-polylactic-co-glycolic acid (laminin-chitosanPLGA) conduits (co group) were used for suturing nerve gaps. The co group performed better than other control 
Table 2 Nerve tissue engineering technology in RLNI animal models

\begin{tabular}{|c|c|c|c|c|c|c|}
\hline $\begin{array}{l}\text { Experiment } \\
\text { (reference) }\end{array}$ & $\begin{array}{l}\text { Animal } \\
\text { model }\end{array}$ & $\begin{array}{l}\text { Experiment } \\
\text { duration }\end{array}$ & Ingredient & Operation & Result & Conclusion \\
\hline $\begin{array}{l}\text { Şentürk et al. } \\
\text { (55) }\end{array}$ & Rats & 16 weeks & $\begin{array}{l}\text { PGA-coated } \\
\text { tube }\end{array}$ & $\begin{array}{c}\text { The tube was inserted into } \\
\text { two nerve stumps and } \\
\text { immobilized with } 8 / 0 \text { PGA } \\
\text { suture material }\end{array}$ & $\begin{array}{c}\text { Compared with other } \\
\text { groups (only transect, } \\
\text { primary repair with } 8 / 0 \\
\text { polypropylene), vocal cord } \\
\text { mobility was proportionally } \\
\text { higher in the experimental } \\
\text { group }\end{array}$ & $\begin{array}{l}\text { The conduit offered } \\
\text { a microenvironment } \\
\text { conducive to accurate } \\
\text { orientation of nerve fibers }\end{array}$ \\
\hline Li et al. (56) & Rats & 12 weeks & $\begin{array}{l}\text { SCs, NSCs, } \\
\text { laminin- } \\
\text { chitosan- } \\
\text { PLGA nerve } \\
\text { conduit }\end{array}$ & $\begin{array}{l}\text { Five-mm-long laminin- } \\
\text { chitosan-PLGA nerve } \\
\text { conduit was sutured } \\
\text { between nerve stumps. } \\
\text { There was a 5-mm gap } \\
\text { between the stumps }\end{array}$ & $\begin{array}{l}\text { Compared with other } \\
\text { groups (SCs only, NSCs } \\
\text { only, null), the diameter and } \\
\text { area of axon regeneration, } \\
\text { the cytokine secretion was } \\
\text { better in the experimental } \\
\text { group. The recovery of vocal } \\
\text { cord motion was similar } \\
\text { between the experimental } \\
\text { group and the autograft } \\
\text { group, better than other } \\
\text { groups }\end{array}$ & $\begin{array}{l}\text { The repair effect of SCs } \\
\text { and NSCs in the laminin- } \\
\text { chitosan-PLGA nerve } \\
\text { conduit was best in the } \\
\text { article, even better than the } \\
\text { autograft group }\end{array}$ \\
\hline Choi et al. (57) & Rabbits & 8 weeks & $\begin{array}{l}\text { PCL/F127 } \\
\text { nerve guide } \\
\text { conduit }\end{array}$ & $\begin{array}{c}\text { PCL/F127 nerve guide } \\
\text { conduit was sutured } \\
\text { between a 10-mm nerve } \\
\text { gap }\end{array}$ & $\begin{array}{l}\text { Compared with the silicone } \\
\text { tube group, vocal cord } \\
\text { movement, thyroarytenoid } \\
\text { muscle status, and nerve } \\
\text { regeneration were all better }\end{array}$ & $\begin{array}{l}\text { The conduit prevented } \\
\text { the influence of fibrous } \\
\text { scar tissue for nerve } \\
\text { regeneration, but } \\
\text { guaranteed nutrients } \\
\text { and oxygen penetration. } \\
\text { Thus, it promoted nerve } \\
\text { regeneration }\end{array}$ \\
\hline $\begin{array}{l}\text { Yoshimatsu } \\
\text { et al. (59) }\end{array}$ & Rats & 8 weeks & $\begin{array}{l}\text { RADA16-I } \\
\text { hydrogels, } \\
\text { silicone tube }\end{array}$ & $\begin{array}{l}\text { An 8-mm silicone tube } \\
\text { bridged a 6-mm nerve gap. } \\
\text { The experimental group } \\
\text { tube was injected with } \\
\text { RADA16-I hydrogel }\end{array}$ & $\begin{array}{l}\text { Compared with other } \\
\text { groups (no RADA16-I, } \\
\text { neurectomy only), the } \\
\text { number of myelinated } \\
\text { nerves was higher and } \\
\text { the area of thyroarytenoid } \\
\text { muscle was large in the } \\
\text { experimental group }\end{array}$ & $\begin{array}{c}\text { The RADA16-I hydrogel } \\
\text { has potential for RLN } \\
\text { regeneration }\end{array}$ \\
\hline
\end{tabular}

RLNI, recurrent laryngeal nerve injury; PGA, polyglycolic acid; SCs, Schwann cells; NSCs, neural stem cells; PLGA, poly-lactic-co-glycolic acid; PCL/F127, polycaprolactone/pluronic F127; BDNF, brain-derived neurotrophic factor; GDNF, glial cell line-derived neurotrophic factor; LBDs, laminin-binding domains; RADA16-I, a self-assembling peptide. 
groups (including the autograft group) (56). In short, nerve tissue engineering technology achieves better results in RLNI repair. Nevertheless, its research and applications are limited. The complications of nerve tissue engineering technology may be associated with stem cells, scaffolds or conduit materials. Moreover, the safety and effectiveness in humans need further validation.

\section{Other treatments}

NFs, stem cells, drugs and voice therapy are applied for RLNI. It is known that NFs promote nerve cell growth, and are therefore widely studied to enhance nerve injury regeneration. Owing to the difficulty of fixing NFs at injury sites, other materials could be used to bind NFs. For example, the concentrations and bioactivities of NFs that were bound with proteins and scaffolds were higher, and the repair effect was better (58). Basic fibroblast growth factor (BFGF) could prevent thyroarytenoid muscle atrophy after injection into muscle (62). Numerous studies have revealed that muscle progenitor cells, HuMSCs, adipose-derived stem cells and bone marrow mesenchymal stem cells with scaffolds were able to repair RLN and improved VCP (61,63-65). Corticosteroids, vitamins and neurotrophic drugs are widely used after RLNI. Other drugs are worth investigating. Nimodipine treatment could improve vocal fold movement $(33,66)$, and tropomyosin receptor kinase A (TrkA) inhibitors could accelerate vocal fold movement recovery by preventing misdirected regeneration (22). Gene therapy has also been applied for RLNI treatment, such as viruses encoding NF gene targeting vocal cord mucosa and laryngeal muscles. Studies have shown that gene therapy was effective in preventing laryngeal muscle atrophy, regenerating nerve fibers, and promoting functional recovery (67).

\section{Summary}

Although the rates of RLNI in the clinical center are very low, they need to be paid attention. Currently, direct suture, nerve anastomosis and reinnervation are still common clinical methods for RLNI by maintaining the continuity of nerves. If the patient develops postoperative hoarseness, this condition may be temporary. Certain drugs should be used also simultaneously. IL, type I thyroplasty and AA are all efficacious and they are feasible treatments since they cause less trauma, and feature convenient operation. Speech therapy seems to be effective too. Nerve tissue engineering technology consists of multiple treatment choices and utilizes conduits/scaffolds with cells, factors, and matrix, which could create a more suitable environment to contribute to nerve regeneration. Therefore, nerve tissue engineering technology is worthy of attention. However, due to several limitations, the evidence is insufficient to date. RLN repair, especially the nerve tissue engineering technology, is deserved more attention.

\section{Acknowledgments}

Funding: This article was supported by Natural Science Foundation of Zhejiang Province (No. LQ20H160023).

\section{Footnote}

Reporting Checklist: The authors have completed the Narrative Review reporting checklist. Available at https:// gs.amegroups.com/article/view/10.21037/gs-21-708/rc

Peer Review File: Available at https://gs.amegroups.com/ article/view/10.21037/gs-21-708/prf

Conflicts of Interest: All authors have completed the ICMJE uniform disclosure form (available at https://gs.amegroups. com/article/view/10.21037/gs-21-708/coif). The authors have no conflicts of interest to declare.

Ethical Statement: The authors are accountable for all aspects of the work in ensuring that questions related to the accuracy or integrity of any part of the work are appropriately investigated and resolved.

Open Access Statement: This is an Open Access article distributed in accordance with the Creative Commons Attribution-NonCommercial-NoDerivs 4.0 International License (CC BY-NC-ND 4.0), which permits the noncommercial replication and distribution of the article with the strict proviso that no changes or edits are made and the original work is properly cited (including links to both the formal publication through the relevant DOI and the license). See: https://creativecommons.org/licenses/by-nc-nd/4.0/.

\section{References}

1. Gambardella C, Polistena A, Sanguinetti A, et al. Unintentional recurrent laryngeal nerve injuries following thyroidectomy: Is it the surgeon who pays the bill? Int J Surg 2017;41 Suppl 1:S55-9.

2. Dionigi G, Wu CW, Kim HY, et al. Severity of Recurrent 
Laryngeal Nerve Injuries in Thyroid Surgery. World J

Surg 2016;40:1373-81.

3. Zhu Y, Gao DS, Lin J, et al. Intraoperative

Neuromonitoring in Thyroid and Parathyroid Surgery. J

Laparoendosc Adv Surg Tech A 2021;31:18-23.

4. Cossa A, Castagnola G, Romeo G, et al. Utility of intraoperative neuromonitoring in detecting recurrent nerve's anatomical anomalies during thyroidectomy. Endocrine 2020;70:194-7.

5. Huang TY, Yu WV, Chiang FY, et al. How the Severity and Mechanism of Recurrent Laryngeal Nerve Dysfunction during Monitored Thyroidectomy Impact on Postoperative Voice. Cancers (Basel) 2021;13:5379.

6. Wujek JR, Lasek RJ. Correlation of axonal regeneration and slow component $\mathrm{B}$ in two branches of a single axon. J Neurosci 1983;3:243-51.

7. Rotshenker S. Wallerian degeneration: the innate-immune response to traumatic nerve injury. J Neuroinflammation 2011;8:109.

8. David S, Zarruk JG, Ghasemlou N. Inflammatory pathways in spinal cord injury. Int Rev Neurobiol 2012;106:127-52.

9. Zuidema JM, Gilbert RJ, Gottipati MK. Biomaterial Approaches to Modulate Reactive Astroglial Response. Cells Tissues Organs 2018;205:372-95.

10. Wang ML, Rivlin M, Graham JG, et al. Peripheral nerve injury, scarring, and recovery. Connect Tissue Res 2019;60:3-9.

11. Harvey AR, Lovett SJ, Majda BT, et al. Neurotrophic factors for spinal cord repair: Which, where, how and when to apply, and for what period of time? Brain Res 2015;1619:36-71.

12. Dzodic R, Markovic I, Santrac N, et al. Recurrent Laryngeal Nerve Liberations and Reconstructions: A Single Institution Experience. World J Surg 2016;40:644-51.

13. Kim HK, Chai YJ, Lee HY, et al. Translational Study on Recurrent Laryngeal Nerve Temperature Susceptibility. J Surg Res 2019;234:7-12.

14. Lynch J, Parameswaran R. Management of unilateral recurrent laryngeal nerve injury after thyroid surgery: A review. Head Neck 2017;39:1470-8.

15. Wu R, Zhang C, Wang H, et al. Clinical observation of end-to-end neuroanastomosis in the treatment of complete injury of the unilateral recurrent laryngeal nerve. Gland Surg 2020;9:2017-25.

16. Sanuki T, Yumoto E, Minoda R, et al. The role of immediate recurrent laryngeal nerve reconstruction for thyroid cancer surgery. J Oncol 2010;2010:846235.

17. Chou FF, Su CY, Jeng SF, et al. Neurorrhaphy of the recurrent laryngeal nerve. J Am Coll Surg 2003;197:52-7.

18. Hong JW, Roh TS, Yoo HS, et al. Outcome with immediate direct anastomosis of recurrent laryngeal nerves injured during thyroidectomy. Laryngoscope 2014;124:1402-8.

19. Simó R, Nixon IJ, Rovira A, et al. Immediate Intraoperative Repair of the Recurrent Laryngeal Nerve in Thyroid Surgery. Laryngoscope 2021;131:1429-35.

20. Bhatt NK, Faddis BT, Paniello RC. Laryngeal adductor function following potassium titanyl phosphate laser welding of the recurrent laryngeal nerve. Laryngoscope 2020;130:1764-9.

21. Gurrado A, Pasculli A, Pezzolla A, et al. A method to repair the recurrent laryngeal nerve during thyroidectomy. Can J Surg 2018;61:278-82.

22. Suzuki H, Araki K, Matsui T, et al. TrkA inhibitor promotes motor functional regeneration of recurrent laryngeal nerve by suppression of sensory nerve regeneration. Sci Rep 2020;10:16892.

23. Wang $W$, Chen $D$, Chen $S$, et al. Laryngeal reinnervation using ansa cervicalis for thyroid surgery-related unilateral vocal fold paralysis: a long-term outcome analysis of 237 cases. PLoS One 2011;6:e19128.

24. Lee WT, Milstein C, Hicks D, et al. Results of ansa to recurrent laryngeal nerve reinnervation. Otolaryngol Head Neck Surg 2007;136:450-4.

25. Wang W, Liu F, Zhang C, et al. Immediate Ansa Cervicalis-to-Recurrent Laryngeal Nerve Anastomosis for the Management of Recurrent Laryngeal Nerve Infiltration by a Differentiated Thyroid Carcinoma. ORL J Otorhinolaryngol Relat Spec 2020;82:93-105.

26. Buyukatalay ZC, Brisebois S, Sirin S, et al. Does Dysphagia Improve Following Laryngeal Reinnervation for Treatment of Hoarseness in Unilateral Vocal Fold Paralysis? J Voice 2021;35:307-11.

27. Zur KB, Carroll LM. Recurrent laryngeal nerve reinnervation in children: Acoustic and endoscopic characteristics pre-intervention and post-intervention. A comparison of treatment options. Laryngoscope 2015;125 Suppl 11:S1-15.

28. Ab Rani A, Azman M, Ubaidah MA, et al. Nonselective Laryngeal Reinnervation versus Type 1 Thyroplasty in Patients with Unilateral Vocal Fold Paralysis: A Single Tertiary Centre Experience. J Voice 2021;35:487-92.

29. Kumai Y, Kodama N, Murakami D, et al. Comparison of vocal outcome following two different procedures 
for immediate RLN reconstruction. Eur Arch Otorhinolaryngol 2016;273:967-72.

30. Li M, Liu F, Shi S, et al. Bridging gaps between the recurrent laryngeal nerve and ansa cervicalis using autologous nerve grafts. J Voice 2013;27:381-7.

31. Li M, Zheng H, Chen S, et al. Selective reinnervation using phrenic nerve and hypoglossal nerve for bilateral vocal fold paralysis. Laryngoscope 2019;129:2669-73.

32. Graham ME, Smith ME. The Nerve to Thyrohyoid Muscle as a Novel Donor Nerve for Laryngeal Reinnervation. Ann Otol Rhinol Laryngol 2020;129:355-60.

33. Mattsson P, Frostell A, Björck G, et al. Recovery of Voice After Reconstruction of the Recurrent Laryngeal Nerve and Adjuvant Nimodipine. World J Surg 2018;42:632-8.

34. Wang CC, Wu SH, Tu YK, et al. Hyaluronic Acid Injection Laryngoplasty for Unilateral Vocal Fold Paralysis-A Systematic Review and Meta-Analysis. Cells 2020;9:2417.

35. Kwon TK, Buckmire R. Injection laryngoplasty for management of unilateral vocal fold paralysis. Curr Opin Otolaryngol Head Neck Surg 2004;12:538-42.

36. Choi N, Jin H, Kim HJ, et al. Early Injection Laryngoplasty With a Long-Lasting Material in Patients With Potentially Recoverable Unilateral Vocal Fold Paralysis. Clin Exp Otorhinolaryngol 2019;12:427-32.

37. Walimbe T, Panitch A, Sivasankar PM. A Review of Hyaluronic Acid and Hyaluronic Acid-based Hydrogels for Vocal Fold Tissue Engineering. J Voice 2017;31:416-23.

38. Wang CC, Chang MH, Jiang RS, et al. Laryngeal electromyography-guided hyaluronic acid vocal fold injection for unilateral vocal fold paralysis: a prospective long-term follow-up outcome report. JAMA Otolaryngol Head Neck Surg 2015;141:264-71.

39. Lahav Y, Malka-Yosef L, Shapira-Galitz Y, et al. Vocal Fold Fat Augmentation for Atrophy, Scarring, and Unilateral Paralysis: Long-term Functional Outcomes. Otolaryngol Head Neck Surg 2021;164:631-8.

40. Lee SW, Kim JW, Chung CH, et al. Utility of injection laryngoplasty in the management of post-thyroidectomy vocal cord paralysis. Thyroid 2010;20:513-7.

41. Friedman AD, Burns JA, Heaton JT, et al. Early versus late injection medialization for unilateral vocal cord paralysis. Laryngoscope 2010;120:2042-6.

42. Lee SW, Park KN. A long-term comparative prospective study between reinnervation and injection laryngoplasty. Laryngoscope 2018;128:1893-7.

43. Jeong GE, Lee DH, Lee YS, et al. Treatment Efficacy of Voice Therapy Following Injection Laryngoplasty for Unilateral Vocal Fold Paralysis. J Voice 2020. [Epub ahead of print].

44. Fancello V, Nouraei SAR, Heathcote KJ. Role of reinnervation in the management of recurrent laryngeal nerve injury: current state and advances. Curr Opin Otolaryngol Head Neck Surg 2017;25:480-5.

45. Ho GY, Leonhard M, Denk-Linnert DM, et al. Preand intraoperative acoustic and functional assessment of the novel APrevent ${ }^{\circledR}$ VOIS implant during routine medialization thyroplasty. Eur Arch Otorhinolaryngol 2020;277:809-17.

46. Sano D, Matsushima K, Isono Y, et al. Long-term treatment outcome of type 1 thyroplasty using novel titanium medialization laryngoplasty implant combined with arytenoid adduction for unilateral vocal cord paralysis: single-arm interventional study at a single institution. Laryngoscope Investig Otolaryngol 2020;5:895-902.

47. Zimmermann TM, Orbelo DM, Pittelko RL, et al. Voice outcomes following medialization laryngoplasty with and without arytenoid adduction. Laryngoscope 2019;129:1876-81.

48. Choi N, Kim Y, Song BH, et al. Effects of Sequentially Combined Arytenoid Adduction and Injection Laryngoplasty in Patients with Unilateral Vocal Fold Paralysis. J Voice 2020. [Epub ahead of print]. doi:10.1016/ j.jvoice.2020.10.004.

49. Rovó L, Ambrus A, Tóbiás Z, et al. A Novel Endoscopic Arytenoid Medialization for Unilateral Vocal Fold Paralysis. Laryngoscope 2021;131:E903-10.

50. Bertelsen C, Reder L. Efficacy of type I thyroplasty after endoscopic cordectomy for early-stage glottic cancer: Literature review. Laryngoscope 2018;128:690-6.

51. Yu WV, Wu CW. Speech therapy after thyroidectomy. Gland Surg 2017;6:501-9.

52. Bonetti A, Šimić I, Živković-Ivanović T. Voice Outcomes as a Results of Voice Therapy after Lobectomy and Thyroidectomy. Acta Clin Croat 2020;59:18-24.

53. Joliat GR, Guarnero V, Demartines N, et al. Recurrent laryngeal nerve injury after thyroid and parathyroid surgery: Incidence and postoperative evolution assessment. Medicine (Baltimore) 2017;96:e6674.

54. Kaneko M, Sugiyama Y, Mukudai S, et al. Effects of Voice Therapy for Dysphonia due to Tension Imbalance in Unilateral Vocal Fold Paralysis and Paresis. J Voice 2020. [Epub ahead of print].

55. Şentürk M, Çakır M, Tekin A, et al. Comparison of primary repair and repair with polyglycolic acid coated 
tube in recurrent laryngeal nerve cuts (an experimental study). Am J Surg 2020;219:632-6.

56. Li Y, Men Y, Wang B, et al. Co-transplantation of Schwann cells and neural stem cells in the laminin-chitosan-PLGA nerve conduit to repair the injured recurrent laryngeal nerve in SD rats. J Mater Sci Mater Med 2020;31:99.

57. Choi JS, Oh SH, An HY, et al. Functional regeneration of recurrent laryngeal nerve injury during thyroid surgery using an asymmetrically porous nerve guide conduit in an animal model. Thyroid 2014;24:52-9.

58. Wang B, Yuan J, Chen X, et al. Functional regeneration of the transected recurrent laryngeal nerve using a collagen scaffold loaded with laminin and laminin-binding BDNF and GDNF. Sci Rep 2016;6:32292.

59. Yoshimatsu M, Nakamura R, Kishimoto Y, et al. Recurrent laryngeal nerve regeneration using a self-assembling peptide hydrogel. Laryngoscope 2020;130:2420-7.

60. Chitose SI, Sato K, Fukahori M, et al. Recurrent laryngeal nerve regeneration using an oriented collagen scaffold containing Schwann cells. Laryngoscope 2017;127:1622-7.

61. Pan Y, Jiao G, Yang J, et al. Insights into the Therapeutic Potential of Heparinized Collagen Scaffolds Loading Human Umbilical Cord Mesenchymal Stem Cells and Nerve Growth Factor for the Repair of Recurrent Laryngeal Nerve Injury. Tissue Eng Regen Med

Cite this article as: Tian $\mathrm{H}, \mathrm{Pan} \mathrm{J}$, Chen $\mathrm{L}, \mathrm{Wu} \mathrm{Y}$. A narrative review of current therapies in unilateral recurrent laryngeal nerve injury caused by thyroid surgery. Gland Surg 2022;11(1):270-278. doi: 10.21037/gs-21-708
2017;14:317-26.

62. Kaneko M, Tsuji T, Kishimoto Y, et al. Regenerative Effects of Basic Fibroblast Growth Factor on Restoration of Thyroarytenoid Muscle Atrophy Caused by Recurrent Laryngeal Nerve Transection. J Voice 2018;32:645-51.

63. Paniello RC, Brookes S, Bhatt NK, et al. Improved adductor function after canine recurrent laryngeal nerve injury and repair using muscle progenitor cells. Laryngoscope 2018;128:E241-6.

64. Li Y, Xu W, Cheng LY. Adipose-derived mesenchymal stem cells accelerate nerve regeneration and functional recovery in a rat model of recurrent laryngeal nerve injury. Neural Regen Res 2017;12:1544-50.

65. Wu W, Zhang S, Chen Y, et al. Biological Function and Mechanism of Bone Marrow Mesenchymal Stem Cellspacked Poly (3,4-ethylenedioxythiophene) (PEDOT) Scaffolds for Peripheral Nerve Injury: The Involvement of miR-21-Notch Signaling Pathway. Curr Neurovasc Res 2017;14:19-25.

66. Hydman J, Björck G, Persson JK, et al. Diagnosis and prognosis of iatrogenic injury of the recurrent laryngeal nerve. Ann Otol Rhinol Laryngol 2009;118:506-11.

67. Araki K, Suzuki H, Uno K, et al. Gene Therapy for Recurrent Laryngeal Nerve Injury. Genes (Basel) 2018;9:316. 